Frequency and outcomes of kidney donation from intensive care patients with acute renal failure requiring renal replacement therapy.

Jo M Sanders

Bachelor of Nursing, Post Grad Diploma Critical Care Science

Donation Specialist Nursing Coordinator, DonateLife Victoria

Helen I Opdam

MBBS, FRACP, FCICM

Consultant Intensive Care Specialist, Austin Health

National Medical Director, Organ and Tissue Authority Canberra

Hayley Furniss

Bachelor of Nursing, Master of Nursing Critical Care

Donation Specialist Nursing Coordinator, DonateLife Victoria

Peter D Hughes

MBBS, FRACP, PhD

Nephrologist, Department of Nephrology, Royal Melbourne Hospital and Department of Medicine (RMH), University of Melbourne

John Kanellis

This is the author manuscript accepted for publication and has undergone full peer review but has not been through the copyediting, typesetting, pagination and proofreading process, which may lead to differences between this version and the Version of Record. Please cite this article as doi: 10.1111/nep.13601

This article is protected by copyright. All rights reserved. 
MBBS, FRACP, PhD

Nephrologist, Department of Nephrology Monash Health and Centre for Inflammatory Diseases, Department of Medicine, Monash University, Melbourne, Australia

Daryl Jones

BSc(Hons), MBBS, FRACP, FCICM, MD, PhD

A/Prof School of Public Health and Preventive Medicine Monash University

Consultant Intensive Care Specialist, Austin Health

Honorary A/Prof Department of Surgery University of Melbourne

\section{Author for correspondence}

Jo Sanders

9 Claronga Street

Bentleigh East, Victoria 3165

Australia

josanders26@gmail.com

This article is protected by copyright. All rights reserved. 


\section{Authorship}

All listed authors have participated sufficiently in the conception and design of this work, as well as the data analysis and writing of the manuscript. Jo Sanders and Hayley Furniss participated in the performance of the research and collection of data. Daryl Jones conducted the data analysis and takes responsibility for the accuracy of the results. All authors contributed to the study design, as well as drafting and revision of the manuscript and all approved the final version.

\section{Disclosures}

The authors of this manuscript do not have any conflicts of interest to disclose. 


\section{Abbreviations}

Acute Kidney Injury (AKI)

Australia and New Zealand Organ Donation (ANZOD)

Donation After Brain Death (DBD)

Donors After Circulatory Death (DCD)

End-Stage Renal Failure (ESRF)

Estimated Glomerular Filtration Rate (eGFR)

Human Leukocyte Antigen (HLA)

Intensive Care Unit (ICU)

Renal Replacement Therapy (RRT)

Standard Criteria Donors (SCD)

Warm Ischemic Time (WIT) 


\begin{abstract}
Background

Kidney transplantation is the preferred treatment for end-stage renal failure. Unfortunately, donor organ shortages prevent many individuals receiving a renal transplant and there is a need to increase the pool of appropriate donors. The presence of acute kidney injury (AKI) in deceased donors has traditionally been a relative contraindication to renal transplantation, even though renal recovery may be favorable in the absence of chronic renal dis-
\end{abstract} ease.

Methods

We undertook an eight-year retrospective observational study of potential deceased organ donors with AKI requiring renal replacement therapy (RRT). We evaluated the rate of successful transplantation as well as short-term and outcomes at a median of $19.5(13.0-52.7)$ months after donation.

Results

Amongst 1058 consented potential organ donors, 39 patients had AKI requiring RRT, of which 19 became donors (13 not medically suitable, 7 didn't proceed to donation). The median (IQR) donor age was 41 (34-50) years and norepinephrine, epinephrine and vasopressin were given to 18,14 and 9 donors, respectively. From the 38 donated kidneys 34 were transplanted. The median (IQR) age of recipients was $53(42.8-58.5)$ years and they were dialysis free in a median (IQR) of 5.5 (2.3-10.8) days. Only minor abnormalities were found at 3 and 6 month renal biopsies, and 2 patients experienced graft failure in the first 12 months.

Conclusions

This article is protected by copyright. All rights reserved. 
Amongst deceased donors with AKI receiving RRT and vasoactive medications outcomes of renal transplantation seems acceptable in the absence of pre-existing renal failure and other donor co-morbidity. Such patients may be an important additional source of kidney donation.

This article is protected by copyright. All rights reserved. 


\section{Introduction}

Dialysis dependent end-stage renal failure (ESRF) is a major cause of morbidity and premature death worldwide, including in the Australian community ${ }^{(1)}$. Renal transplantation is the preferred treatment for ESRF and is associated with improved survival, quality of life and cost savings in the medium to longer term ${ }^{(2)}$. Most transplanted kidneys are derived from the small number of circumstances where organ donation is feasible, in patients who have died from a fatal illness in an intensive care unit (ICU) ${ }^{(3)}$. Due to shortages of appropriate donor organs, many patients wait for several years on dialysis before receiving a transplant and a significant proportion die prior to transplantation. It is therefore important to maximize the availability of donor organs through strategies such as the use of live kidney donors, deceased donors after circulatory death (DCD) and other nontraditional deceased donors.

The presence of acute kidney injury (AKI) in the deceased donor has been a relative contraindication to renal transplantation ${ }^{(4-16)}$ and is associated with higher rate of kidney nonutilization $^{(17)}$. This is despite the fact that studies of the epidemiology of AKI in the Intensive Care Unit (ICU) suggest that renal recovery is likely in the absence of chronic renal disease ${ }^{(18)}$. A number of previous studies of transplanting kidneys from donors with AKI report a high rate of delayed graft function but satisfactory longer-term transplant outcomes $^{(19,20)}$.

Most of these reports are from the perspective of renal transplant units ${ }^{(4-16)}$ and include donors with only mild forms of $\mathrm{AKI}^{(4,6,7,9,10,13,16,20)}$ or standard criteria donors (SCD) with 
brain death ${ }^{(4,5,11,15,16)}$ and provide limited information about donor characteristics or selection.

There is much less information on the frequency and outcome of kidney procurement and transplantation from potential donors with AKI requiring renal replacement therapy. Accordingly, we undertook an eight-year retrospective observational study of potential deceased organ donors in the states of Victoria and Tasmania in Australia. Specifically, we assessed the frequency with which such patients were referred to donation services, reasons for exclusion, as well as rates of evolution to organ donation and subsequent procurement. In addition, we assessed short term renal graft function, as well as occurrence of rejection episodes, proteinuria and biopsy findings within the first 6 months of transplantation. Finally, we evaluated the frequency of graft failure in the first 12 months.

\section{Materials and methods}

\section{Ethics approval}

Ethics approval to conduct the study was obtained from the Australian Red Cross Blood Service (Blood Service) Human Research Ethics Committee (approval number 2013\#10) and waiver of informed written consent was provided due to the audit nature of the study. To ensure the confidentiality and privacy of organ donors and their families, patient files were reviewed by a donor coordinator in a de-identified manner.

\section{Overview of DonateLife Victoria}

This article is protected by copyright. All rights reserved. 
DonateLife Victoria is an affiliated agency of the Blood Service and provides donor coordination services within the states of Victoria and Tasmania. Donor coordinators assess referred potential donors for medical suitability, collect detailed medical information, obtain legal consents and make organ offers to transplant units.

Medical information about the donor patient was obtained from the hospital medical record, the patient's family and other health providers including general practitioners and is documented in a confidential donor file. This includes the hospital admission course and cause of death, past medical history, and assessment of risks for transmissible infectious

disease. Further detailed information is collected on physiological variables and supportive treatments, pathology and radiology investigation results.

Advice regarding organ suitability for transplantation is obtained initially at the time of donor assessment and at organ procurement from medical donation specialist staff who are practicing intensivists and transplant unit medical specialist staff.

\section{Data sources and study design}

We undertook a retrospective audit of all potential organ donor case files within the state of Victoria and Tasmania between 1st January 2008 and 31st December 2015. Donor records assessed included those with potential for donation after brain death (DBD) and donation after circulatory death (DCD). Data extracted for the study were pertinent data elements routinely collected in the donor assessment process and entered into the confiden- 
tial donor file. Recipient outcome data was obtained from recipient renal transplant unit physicians and were data elements routinely collected during the usual treatment and monitoring of patients after kidney transplantation.

\section{Data collected on potential organ donors}

We extracted information on donor age, gender, blood group, cause of death, ICU treatments including use and dose of vasoactive drugs and provision of renal replacement therapy (RRT), and pathway of donation (DCD or DBD). Past health history information collected included prior renal function (if pre-admission urea and creatinine levels available), risk factors for renal disease (history of hypertension, hyperlipidemia, diabetes mellitus or smoking) and any documented renal disease. Renal function information during the hospital admission included urine output and initial presenting and final (terminal) serum creatinine. Oliguria was defined as urine output less than $20 \mathrm{mls} / \mathrm{hour}$ for 3 or more consecutive hours and was obtained from ANZOD (Australia and New Zealand Organ Donation) Registry. AKI was defined as an abrupt decline in renal function as evidenced by oliguria and rising serum urea and creatinine. Organ procurement details included anatomy, biopsy results, only if undertaken and whether the kidneys that were procured were transplanted. Data is reported for donors overall as well as donation via the DCD and BD pathways.

\section{Data collected on kidney transplant recipients}

This article is protected by copyright. All rights reserved. 
For each transplant recipient we extracted information on age, gender, cause of renal failure, dialysis history (years, type), prior transplantation history, details of donor specific antibodies, and Human Leukocyte Antigen (HLA) mismatches. Data on immunosuppression regimens was not available. Kidney machine perfusion technology for organ assessment and preservation was not used in any of the donation cases in this report. Cold ischemic time was less than 24 hours in all cases.

\section{Data on outcome and function of transplanted kidneys}

We assessed whether the recipient required inpatient dialysis within the first week after transplant (the usual definition of delayed graft function) or later during the admission and whether they required ongoing dialysis at the time of hospital discharge. In addition, we recorded the number of rejection episodes and graft function at 6 months posttransplantation, as well as the renal function at the time of data acquisition.

\section{Details of data analysis}

Distributed data are described in terms of the range, median and inter-quartile range (IQR). Numerical data are presented as numbers and proportions. Comparison of distributed data was conducted with the Mann-Whitney $\mathrm{U}$ test, and proportions were compared with the chi-square or Fisher's exact test as appropriate. In all cases, a two-sided p-value of $<0.05$ was taken to indicate statistical significance.

This article is protected by copyright. All rights reserved. 


\section{Results}

Overall characteristics of the donor cohort

There were 1058 consented and assessed deceased potential organ donors in the 2 states of Victoria and Tasmania between 1st Jan 2008 and 31st Dec 2015 (Figure 1). Amongst these patients, 495 (46.7\%) had oliguria during their hospital admission. Among the 495 oliguric patients, 39 patients $(7.8 \%)$ required RRT to treat complications of AKI (Figure 1).

\section{Details of potential donors on RRT}

Among the 39 patients with $\mathrm{AKI}$ requiring RRT, 13 were considered to be not medically suitable for donation, for the following reasons: end stage renal failure (3); received current renal transplant (1); risk to recipient (hepatitis B virus, unknown cause of death) (2), and medical co-morbidities (7).

Thus, there were 26 patients who proceeded to planned organ donation. Amongst these 26 patients, 7 patients did not proceed to organ procurement of kidneys. In 4 cases of planned donation after circulatory death the patient did not die within the accepted time frames for kidney donation. In the other 3 cases, intra-operative renal biopsies revealed cortical necrosis, interstitial fibrosis and tubular atrophy.

\section{Details of eventual kidney donors}

Among the 19 eventual organ donors, 7 (36.8\%) were female and the median (IQR) age was 41 (34-50) years. Thirteen (68.4\%) patients were brain dead at the time of donation 
and hypoxic brain injury was the major cause of death (Table 1). Pre-admission urea and creatinine were available in $14(73.7 \%)$ and $13(68.4 \%)$ of patients, respectively, and was within normal laboratory ranges in all cases. The median (IQR) pre-admission urea and creatinine were $4.3(2.6-5.1) \mathrm{mmol} / \mathrm{L}$, and 70 (52.5-87.0) umol/L, respectively.

The median (IQR) urea and creatinine at the time of hospital presentation were 6.3 (4.98.3) $\mathrm{mmol} / \mathrm{L}$ and $120(66-168) \mathrm{umol} / \mathrm{L}$, respectively. Oliguria was present for a median (IQR) of 50 (29-86) hours, and the median terminal (final hour) urine output was 15 (2-40) $\mathrm{ml} / \mathrm{hr}$. The terminal urea and creatinine were available in 18 and 19 patients, respectively, and were 15.5 (10.6-21) mmol/L and 179 (129-377) umol/L, respectively, noting that all patients had or were receiving RRT. RRT was provided for 13 patients within 24 hours of donation, a further patient within 24 to 48 hours of donation and in 4 patients only prior to 48 hours of donation. In 1 patient the time of cessation of RRT was not documented.

Of the 19 kidney donors, 18 received norepinephrine with a median (IQR) lowest and highest does of $1.0(1.0-13.0)$ and $32.5(9.8-46.3) \mathrm{mcg} / \mathrm{min}$, respectively. In addition, 14 received epinephrine, with a median (IQR) lowest and highest dose of 1.5 (1.0-5.0) and $13.5(9.5-30.0) \mathrm{mcg} / \mathrm{min}$, respectively. Furthermore, 9 patients received arginine vasopressin with a median (IQR) dose of $2.4(2.0-3.0)$ units/hr.

Differences in features of kidney donors and patients excluded for medical co-morbidities 
The features of those patients in whom eventual kidney procurement occurred were compared with the 7 patients deemed not medically suitable due to co-morbidities, in order to provide insight into clinician decision making regarding suitability and to determine whether the characteristics of these patients differed. There were clinically important and statistical differences with the group proceeding to donation being younger, more likely to donate via the brain death pathway and having less pre-existing hypertension, hyperlipidemia and diabetes (Table 1). There were however, no difference in hours of oliguria $(p=0.306)$; premorbid urea $(p=0.28)$; pre-morbid creatinine $(p=0.16)$; presenting urea $(p=0.306)$; presenting creatinine $(p=0.135)$; terminal urea $(p=0.16)$; terminal creatinine $(p=1.0)$; lowest norepinephrine dose $(p=0.67)$; highest norepinephrine dose $(p=0.58)$; lowest epinephrine dose $(p=0.89)$; highest epinephrine dose $(p=0.80)$; or vasopressin dose $(p=0.60)$. Five of the 7 patents deemed not medically suitable due to co-morbidities were to donate via the DCD pathway.

\section{Details of kidneys procured and reasons for exclusion}

Nineteen patients with AKI requiring RRT underwent organ procurement resulting in 38 kidneys, 34 of which were transplanted. Four kidneys were unsuitable for transplantation due to surgical damage during retrieval (2), poor perfusion post retrieval (1) or renal biopsy features (50\% cortical necrosis) post retrieval (1) (Figure 1).

Only 15 donor kidneys were biopsied from 8 potential donors. In 6 kidneys intra-operative biopsies were performed which revealed severe cortical necrosis and hence were unsuitable for transplantation (Figure 1). In addition, 9 kidneys were biopsied post retrieval. Of 
these, 1 was deemed unsuitable as it displayed $50 \%$ cortisol necrosis, while the remaining 8 revealed only mild tubular injury and were transplanted.

\section{Demographic details of renal transplant recipients}

Amongst the 34 transplant recipients, 16 (47.1\%) were female, and the median (IQR) age was 53.0 (42.8-58.5) years. The median (IQR) pre-transplant duration of dialysis was 36.5 (18.0-48.3) months, and patients received hemodialysis, peritoneal dialysis, or both modalities in $20(58.8 \%), 13(38.2 \%)$ and $1(2.9 \%)$ instances, respectively with no patients transplanted pre-emptively. Nine (26.5\%) recipients had diabetes, and 6 (17.6\%) patients had received previous renal transplants. The median (IQR) number of HLA mismatches was 3 (1-4). The underlying cause of the end-stage renal failure was diabetes mellitus (7); polycystic kidney disease (6), IgA nephropathy (21), reflux nephropathy (21), focal segmental glomerulosclerosis (4), glomerulonephritis (3) and other (4).

There were no significant differences between the 6 DCD and 13 BD donors in relation to median age $(p=0.58)$, gender $(p=0.83)$, cause of death $(p=0.25)$, pre-existing hypertension $(p=0.31)$, hyperlipidemia $(p=0.94)$, diabetes $(p=0.13)$, or smoking status $(p=0.69)$. However, patients who donated via the DCD pathway had a higher median (IQR) terminal urine output than those donating via the BD pathway $(50.0$ [26.3 - 77.5] 5.0 [1.0 - 22.5] $\mathrm{ml} / \mathrm{hr}$, respectively; $\mathrm{p}=0.022$ ). 


\section{Short-term outcomes of renal transplant recipients}

The median (IQR) number of days until being free of dialysis was available in 32 recipients and was $5.5(2.3-10.8)$ days. At 2 weeks post-transplantation, 30 patients were dialysis free and 4 were still requiring dialysis. The median (IQR) number of days from surgery until hospital discharge was available in 32 patients and was 8 (6-11) days. One recipient unexpectedly developed renal vessel thrombosis associated with graft failure on day 13 , having required dialysis for 9 days in the immediate post-operative period.

\section{Longer term outcomes of renal transplant recipients}

The median (IQR) serum creatinine at 3 and 6 months was 116 (98-156) and 108 (91-149) umol/L, respectively. Renal biopsies were performed in 26 (76.5\%) of patients at 3 months, and $12(35.3 \%)$ of patients at 6 months. Amongst the renal biopsies, only minor abnormalities were found (Table 2). In the 31 patients with results available, there was no significant proteinuria at 3 or 6 months. In the first 12 months, 1 patient experienced 3 rejection episodes, 2 patients experienced 2 rejections, and 7 patients experienced 1 rejection episode. Two patients experienced graft failure in the first 12 months; at day 13 , and 3 months due to severe rejection. These grafts were from 2 separate donors and the other transplanted kidney of the first was functioning satisfactorily at 6 months follow-up post transplantation. The pair to the second was not transplanted due to mild acute tubular injury found on biopsy post organ retrieval.

There were 22 and 12 recipients of kidneys donated via the BD and DCD pathways, respectively. At the time of review 1 patient in each group had died of malignancy. There 
were 3 patients in whom the graft had failed (2 in BD, 1 in DCD). Amongst the remaining 29 patients the median (IQR) duration between the transplantation and final review was 19.5 (13.0-52.7) months, and 5 patients in the BD were listed as being well or having a functioning graft. Amongst the 24 patients with an available test, the median (IQR) creatinine was 117 (88.5-135.2) micromol/L. There was no difference in the median (IQR) creatinine at time of review which was $112.5(81.5-124)$ and $118.5(98.3-158)$ micromol/L for BD and DCD patients, respectively $(p=0.212)$.

The usual approach to immunosuppression was basiliximab induction followed by tacrolimus, mycophenolate and prednisolone. 


\section{Discussion}

\section{Summary of major findings}

Proceeding with donation of kidneys from potential donors in ICU with AKI requiring RRT resulted in 34 additional patients receiving kidney transplants over an 8 year period in the states of Victoria and Tasmania of Australia. Thirty-two grafts were functioning at 6 months post-transplant, with graft failure having occurred in 2 recipients. During this period there were 1309 kidney transplants from deceased donors from this same region, with these 34 transplants representing $2.6 \%$ of the total performed (ANZOD Registry). During the period of the study Victorian and Tasmania did not have in place a policy of routine referral to donation services of all patients undergoing end-of-life care in intensive care, with donor identification largely reliant on treating clinical staff. It is likely that there may have been other patients with AKI undergoing end-of-life care in ICUs who were not referred to donor services due to treating staff deeming them unsuitable to donate due to organ failure. These 34 additional renal transplants may therefore represent only a portion of the additional renal transplants possible if potential donors with severe AKI were to be routinely considered for kidney donation.

The 19 donors with AKI had normal prior renal function and a relatively low frequency of cardiovascular risk factors. Compared with average donor characteristics in Australia during this period, these AKI donors were younger, less likely to have hypertension or be current smokers, though were more likely to be diabetic ${ }^{(21,22)}$. Potential donors with AKI deemed not medically suitable because of co-morbidities during this same period were older, less likely to have brain death and had more cardiovascular risk factors and prior renal disease. 


\section{Comparison with previous studies}

Similar to other studies that have reported on transplanting kidneys from donors with AKI, our study found a high rate of delayed graft function with satisfactory longer-term graft function. ${ }^{(19,23)}$

Our study included a broad cohort of both standard and expanded criteria donors. Most reports of transplanting kidneys with AKI focus on young, standard criteria donors who have otherwise excellent kidney donor characteristics ${ }^{(4,5,11,13,16,24,25)}$. A common finding is of an increased incidence of delayed graft function, but similar short and intermediate term graft function and survival compared with standard criteria donors without AKI. Expanded criteria kidney donors are associated with reduced graft function at one-year and long-term graft survival ${ }^{(26)}$. It is unclear whether AKI in an expanded criteria donor will compound this effect on graft function and survival. A large study from Brazil reported no difference in renal function at 1 year post transplantation for kidneys with AKI compared with those without for both standard and expanded criteria donors ${ }^{(20)}$. Similarly, a single center renal transplant unit reported excellent short-term graft outcomes in recipients of both standard and expanded criteria donor kidneys with AKI including those with severe AKI requiring RRT ${ }^{(8)}$. However, a US Scientific Registry of Transplant Recipients Report found an association with higher graft loss in expanded criteria donor kidneys but not standard donor criteria kidneys when there was more severe AKI as evidenced by higher donor serum creatinine levels ${ }^{(17)}$. A further large registry study from the UK found that AKI 
was associated with delayed graft function but also inferior graft function and a small reduction in graft survival at 1 year; more severe grades of AKI were associated with primary non-function ${ }^{(23)}$.

Our study reports kidney transplantation from deceased donors with the most severe form of $\mathrm{AKI}$, in that all donors required RRT as part of their final illness in intensive care. Many studies have reviewed the experience of proceeding with kidney donation and transplantation in donors with lesser degrees of $\mathrm{AKI}^{(4,6,7,9,10,13,16,20,27)}$ Intuitively, mild or improving donor AKI prior to kidney procurement and transplantation would seem less likely to impact on recipient graft outcomes compared to severe AKI. Interestingly Morgan reported no difference in rates of delayed graft function from a young cohort of donors with AKI irrespective of whether the creatinine was still rising or falling prior to procurement ${ }^{(13)}$. Also, contrary to what one might expect, a report by Hall found there to be no association of sixmonth kidney function (estimated Glomerular Filtration Rate (eGFR)) with severity of AKI in fact, the higher the Acute Kidney Injury Network grade the better the outcomes ${ }^{(19)}$. This is possibly due to selection bias as only the 'best' donor kidneys with very severe AKI were utilized. A more recent publication by Hall provided 3 year recipient outcome data from a large cohort of AKI donors and found no difference in graft survival according to AKI stage, although no donors received $\mathrm{RRT}^{(27)}$. Excellent short-term graft outcomes were reported in a single center study which included donors with severe AKI requiring RRT ${ }^{(8)}$.

Our report also included a broad cohort of donors including DCD as well as DBD donors whereas the majority of previous studies have included only DBD donors. $(4-6,10,11,15,16,28)$ DCD is known to be associated with an increased incidence of delayed graft function. 
Many reports have suggested that long term kidney function from DCD and DBD donors are identical. Nevertheless, our report indicates that even with the combined insults of AKI and the ischemia associated with the DCD pathway, transplantation of such kidneys can result in excellent graft outcomes.

This study reports all potential donor cases in a region of Australia, rather than the perspective of a single renal transplant unit and provides more detailed information on donor characteristics and selection compared to previous studies ${ }^{(4,6-16,27)}$. This report therefore might assist organ procurement organizations and clinicians tasked with determining whether to proceed with donation and kidney procurement in potential organ donors with AKI.

\section{Study strengths and limitations}

This study includes a broad cohort of deceased donors, including DBD and DCD donors, SCD and expanded criteria donors, and focuses on donors with the most severe form of AKI for whom proceeding with kidney donation and transplantation may be most controversial. It also provides information about decision making including reasons why donors and kidneys were not used. Donor data elements were collected prospectively.

It does not provide information about kidney utilization in potential donors with lesser degrees of AKI and is not a comparative study. It provides only limited short term follow-up of recipients and graft function. Due to its small size it is not able to provide reliable information to assist in precise donor and organ characteristics that predict a satisfactory 
transplantation outcome. It was also not possible to determine the features of recipients who might best benefit from donor organs with AKI, particularly if there are other concerns such as expanded criteria donor features or donation occurring via the DCD pathway, or whether a modified approach to immunosuppression is warranted. It also does not provide any information about the usefulness or otherwise of machine perfusion in the further assessment and preservation of these kidneys, as this technology was not used in any of the donation cases in this report.

\section{$\underline{\text { Implications for clinicians and policy makers }}$}

Potential donors with AKI provide an additional pool of kidney donors. It is important that clinicians in the intensive care and donation sector care sectors do not dismiss potential donors with severe $\mathrm{AKI}$ as unsuitable to donate kidneys for transplantation. It is also important that renal transplant physicians consider utilizing such offered organs for transplantation and that systems exist to target the offer of these kidneys to recipients who are most able to benefit from them.

\section{Areas for future research}

Renal transplantation from deceased donors with AKI who have otherwise good kidney donor characteristics (younger age, few vascular risk factors and other co-morbidities, and particularly those donating after neurological determination of death) has a high level of evidence to support good transplantation outcomes in appropriate recipients. When there are some unfavorable donor characteristics, such as expanded donor criteria or donation occurring after circulatory death, it is uncertain whether it is possible to proceed and still 
have satisfactory renal transplant outcomes. Prospective data collection on kidney transplantation from donors with AKI that includes documentation of donor characteristics and review of recipient outcomes will further inform when kidney transplantation from donors with AKI is worthwhile and may help in determining recipient selection. The utility of machine perfusion to further evaluate these kidneys and possibly improve function is another area for future exploration.

This article is protected by copyright. All rights reserved. 


\section{Conclusions}

In our study of ICU patients with AKI requiring RRT, selecting young patients with previously normal renal function and few co-morbidities resulted in an additional 34 donated kidneys with favorable 6-month function. Such patients are an important source of additional donors for patients suffering end-stage renal failure.

\section{Acknowledgements}

We wish to acknowledge all of the donor coordinators in participating hospitals who collected data as part of routine organ donation procedures. 
References

1. ANZDATA Registry. 39th Report C. Incidence of End Stage Kidney Disease. Australia and New Zealand Dialysis and Transplant Registry, Adelaide, Australia. 2007.

2. Wolfe RA, Ashby VB, Milford EL, Ojo AO, Ettenger RE, Agodoa LY, et al. Comparison of mortality in all patients on dialysis, patients on dialysis awaiting transplantation, and recipients of a first cadaveric transplant. N Engl J Med. 1999;341(23):1725-30.

3. ANZOD Registry AR, Section 2. Overview of Organ Donation Activity in Australia and New Zealand. Australia and New Zealand Dialysis and Transplant Registry, Adelaide, Australia. 2017.

4. Al Khader AA, Shaheen FA, Attar BA, Elamin KM, Al Ghamdi F, Jondeby M. Successful use of kidneys from deceased donors with acute renal failure. Prog Transplant. 2007;17(4):258-63.

5. Anil Kumar MS, Khan SM, Jaglan S, Heifets M, Moritz MJ, Saeed MI, et al. Successful transplantation of kidneys from deceased donors with acute renal failure: Threeyear results. Transplantation. 2006;82(12):1640-5.

6. Deroure B, Kamar N, Depreneuf H, Jacquet A, Francois H, Charpentier B, et al. Expanding the criteria of renal kidneys for transplantation: use of donors with acute renal failure. Nephrol Dial Transplant. 2010;25(6):1980-6.

This article is protected by copyright. All rights reserved. 
7. Farney AC, Rogers J, Orlando G, al-Geizawi S, Buckley M, Farooq U, et al. Evolving experience using kidneys from deceased donors with terminal acute kidney injury. $\mathrm{J}$ Am Coll Surg. 2013;216(4):645-55; discussion 55-6.

8. Heilman RL, Smith ML, Kurian SM, Huskey J, Batra RK, Chakkera HA, et al. Transplanting Kidneys from Deceased Donors With Severe Acute Kidney Injury. Am J Transplant. 2015;15(8):2143-51.

9. Jacobi J, Rebhan D, Heller K, Velden J, Hilgers KF, Wullich B, et al. Donor acute kidney injury and short-term graft outcome in renal transplantation. Clin Transplant. 2014;28(10):1131-41.

10. Jun H, Jung CW, Lim S, Kim MG. Kidney Donor Risk Index as the Predictor for the Short-term Clinical Outcomes After Kidney Transplant From Deceased Donor With Acute Kidney Injury. Transplant Proc. 2017;49(1):88-91.

11. Mekeel KL, Moss AA, Mulligan DC, Chakkera HA, Hamawi K, Mazur MJ, et al. Deceased donor kidney transplantation from donors with acute renal failure due to rhabdomyolysis. Am J Transplant. 2009;9(7):1666-70.

12. Molina M, Apaza J, Gonzalez Monte E, Gutierrez Martinez E, Sevillano AM, Marin JP, et al. Results of kidney transplantation from deceased donors with acute kidney injury. Transplant Proc. 2015;47(1):42-4.

13. Morgan C, Martin A, Shapiro R, Randhawa PS, Kayler LK. Outcomes after transplantation of deceased-donor kidneys with rising serum creatinine. Am J Transplant. 2007;7(5):1288-92. 
14. Navarro AP, Sohrabi S, Wilson C, Sanni A, Wyrley-Birch H, Vijayanand D, et al. Renal transplants from category III non-heart-beating donors with evidence of pre-arrest acute renal failure. Transplant Proc. 2006;38(8):2635-6.

15. Ugarte R, Kraus E, Montgomery RA, Burdick JF, Ratner L, Haas M, et al. Excellent outcomes after transplantation of deceased donor kidneys with high terminal creatinine and mild pathologic lesions. Transplantation. 2005;80(6):794-800.

16. Zuckerman JM, Singh RP, Farney AC, Rogers J, Stratta RJ. Single center experience transplanting kidneys from deceased donors with terminal acute renal failure. Surgery. 2009;146(4):686-94; discussion 94-5.

17. Kayler LK, Garzon P, Magliocca J, Fujita S, Kim RD, Hemming AW, et al. Outcomes and utilization of kidneys from deceased donors with acute kidney injury. Am J Transplant. 2009;9(2):367-73.

18. Gallagher M, Cass A, Bellomo R, Finfer S, Gattas D, Lee J, et al. Long-term survival and dialysis dependency following acute kidney injury in intensive care: extended followup of a randomized controlled trial. PLoS Med. 2014;11(2):e1001601.

19. Hall IE, Schroppel B, Doshi MD, Ficek J, Weng FL, Hasz RD, et al. Associations of deceased donor kidney injury with kidney discard and function after transplantation. Am J Transplant. 2015;15(6):1623-31.

20. Klein R, Galante NZ, de Sandes-Freitas TV, de Franco MF, Tedesco-Silva H, Medina-Pestana JO. Transplantation with kidneys retrieved from deceased donors with acute renal failure. Transplantation. 2013;95(4):611-6.

21. ANZOD Registry AR, Chapter 4. Donor Profile. Australia and New Zealand Dialysis and Transplant Registry, Adelaide, Australia. 2015. 
22. ANZOD Registry AR, Section 4. Deceased Organ Donor Profile. Australia and New Zealand Dialysis and Transplant Registry, Adelaide, Australia. 2017.

23. Boffa C, van de Leemkolk F, Curnow E, Homan van der Heide J, Gilbert J, Sharples E, et al. Transplantation of Kidneys From Donors With Acute Kidney Injury: Friend or Foe? Am J Transplant. 2017;17(2):411-9.

24. Bacak-Kocman I, Peric M, Kastelan Z, Kes P, Mesar I, Basic-Jukic N. First documented case of successful kidney transplantation from a donor with acute renal failure treated with dialysis. Int Urol Nephrol. 2013;45(5):1523-6.

25. Bilgic A, Erdogan B, Kali A, Buyukbakkal M, Eser B, Bozkurt B, et al. Successful kidney transplantation from a cadaveric donor unsuitable for other centers due to acute renal failure: a case report. Transplant Proc. 2012;44(6):1764-6.

26. Ojo AO. Expanded criteria donors: process and outcomes. Semin Dial. 2005;18(6):463-8.

27. Hall IE, Akalin E, Bromberg JS, Doshi MD, Greene T, Harhay MN, et al. Deceaseddonor acute kidney injury is not associated with kidney allograft failure. Kidney Int. 2019;95(1):199-209.

28. Lee MH, Jeong EG, Chang JY, Kim Y, Kim JI, Moon IS, et al. Clinical outcome of kidney transplantation from deceased donors with acute kidney injury by Acute Kidney Injury Network criteria. J Crit Care. 2014;29(3):432-7. 
Table 1: Characteristics of eventual kidney donors versus those determined to be not medically suitable due to co-morbidities

\begin{tabular}{|c|c|c|c|}
\hline Variable & $\begin{array}{l}\text { Potential donors ex- } \\
\text { cluded due to co- } \\
\text { morbidities }\end{array}$ & Kidney donors & $p$-value \\
\hline Number & 7 & 19 & - \\
\hline $\begin{array}{l}\text { Age median (IQR) } \\
\text { years }\end{array}$ & $63(46-67)$ & $41(34-50)$ & 0.013 \\
\hline $\begin{array}{l}\text { Male gender } \\
N(\%)\end{array}$ & $6(85.7)$ & $12(63.2)$ & 0.27 \\
\hline $\begin{array}{l}\text { Donation via DCD } \\
\mathrm{N}(\%)\end{array}$ & $5(71.4)$ & $6(31.6)$ & 0.068 \\
\hline $\begin{array}{c}\text { Cause of death N (\%) } \\
\text { Cerebral infarction } \\
\text { Cerebral oedema } \\
\text { Cerebral hypoxia } \\
\text { Intracranial bleed } \\
\text { Multi-organ failure } \\
\text { Respiratory failure }\end{array}$ & $\begin{array}{c}1(14.3) \\
0 \\
6(85.7) \\
0 \\
0 \\
0\end{array}$ & $\begin{array}{c}1(5.3) \\
3(15.8) \\
12(63.2) \\
1(5.3) \\
1(5.3) \\
1(5.3)\end{array}$ & 0.68 \\
\hline Hypertension N (\%) & $5(71.4)$ & $2(10.5)$ & 0.002 \\
\hline High cholesterol N (\%) & $4(57.1)$ & $3(15.8)$ & 0.035 \\
\hline $\begin{array}{l}\text { Prior kidney disease } \\
\mathrm{N}(\%)\end{array}$ & $1(14.3)$ & 0 & 0.093 \\
\hline Diabetes N (\%) & $5(71.4)$ & $4(21.1)$ & 0.017 \\
\hline $\begin{array}{l}\text { Smoking status N (\%) } \\
\text { Current } \\
\text { Never } \\
\text { Previous }\end{array}$ & $\begin{array}{l}3(42.9) \\
3(42.9) \\
1(14.3)\end{array}$ & $\begin{array}{c}5(26.3) \\
10(52.6) \\
4(21.1)\end{array}$ & 0.71 \\
\hline
\end{tabular}

This article is protected by copyright. All rights reserved. 
$\mathrm{N}=$ Number, IQR = inter-quartile range, DCD = donation after circulatory death,

This article is protected by copyright. All rights reserved. 
Table 2: Details of renal outcome measures at 3 and 6 months

\begin{tabular}{|c|c|c|}
\hline Variable & Values at 3 months & Values at 6 months \\
\hline $\begin{array}{l}\text { Serum creatinine } \\
\text { Median (IQR) umol/L }\end{array}$ & $\begin{array}{c}116.0(98.0-156.0) \\
N=33\end{array}$ & $\begin{array}{c}107.5(90.8-149.3) \\
N=32\end{array}$ \\
\hline $\begin{array}{l}\text { eGFR } \\
\text { Median (IQR) } \mathrm{mL} / \mathrm{min}\end{array}$ & $\begin{array}{c}46.0(35.8-62.5) \\
N=28\end{array}$ & $\begin{array}{c}51(45-61) \\
N=27\end{array}$ \\
\hline $\begin{array}{l}\text { Renal biopsy } \\
\text { - Not done } \\
\text { - Normal } \\
\text { - Abnormal }\end{array}$ & $\begin{array}{c}8 \\
11 \\
15\end{array}$ & $\begin{array}{c}22 \\
2 \\
10\end{array}$ \\
\hline $\begin{array}{l}\text { Findings of renal biopsies } \\
\text { - Interstitial fibrosis } \\
\text { - Tubular atrophy } \\
\text { - Glomerulosclerosis } \\
\text { - Chronic rejection } \\
\text { - Calcineurin inhibitor toxicity } \\
\text { - Renovascular disease }\end{array}$ & $\begin{array}{l}\text { Mild (7) } \\
\text { Mild (7) } \\
\text { Not detected } \\
\text { Mild (8) } \\
\text { Mild (2), Moderate (1) } \\
\text { Moderate (2) }\end{array}$ & $\begin{array}{l}\text { Mild (7), Moderate (2) } \\
\text { Mild (7), Moderate (2) } \\
\text { Mild (1) } \\
\text { Mild (1) } \\
\text { Mild (1) } \\
\text { Moderate (1) }\end{array}$ \\
\hline
\end{tabular}

eGFR = estimated glomerular filtration rate, IQR = inter-quartile range

This article is protected by copyright. All rights reserved. 
Figure 1. Flow diagram of patients considered for donation and outcomes

Oliguria was defined as urine output $<20 \mathrm{ml} /$ hour for 3 or more consecutive hours.

$\mathrm{RRT}=$ renal replacement therapy. $\mathrm{AKI}=$ acute kidney injury. WIT $=$ warm ischemic time

This article is protected by copyright. All rights reserved. 


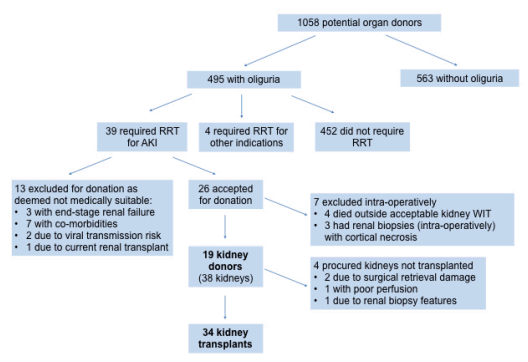

NEP_13601_Nephrology_AKI_CVVHDF figure 1_011218.001.tiff

This article is protected by copyright. All rights reserved. 


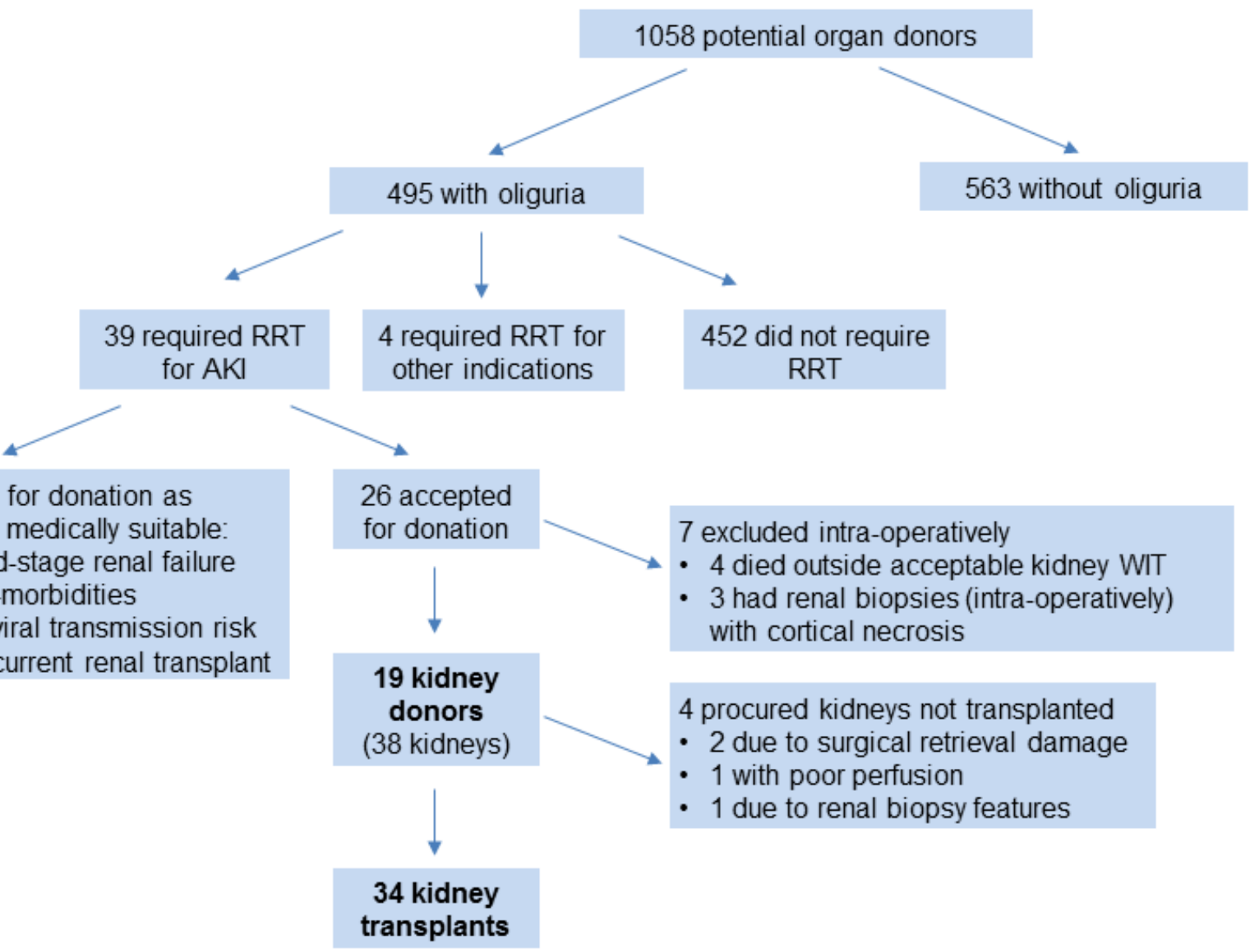

This article is protected by copyright. All rights reserved. 


\section{University Library}

\section{- M M N E R VA A gateway to Melbourne's research publications}

Minerva Access is the Institutional Repository of The University of Melbourne

Author/s:

Sanders, JM;Opdam, HI;Furniss, H;Hughes, PD;Kanellis, J;Jones, D

Title:

Frequency and outcomes of kidney donation from intensive care patients with acute renal failure requiring renal replacement therapy

Date:

2019-12-01

Citation:

Sanders, J. M., Opdam, H. I., Furniss, H., Hughes, P. D., Kanellis, J. \& Jones, D. (2019). Frequency and outcomes of kidney donation from intensive care patients with acute renal failure requiring renal replacement therapy. NEPHROLOGY, 24 (12), pp.1296-1303. https:// doi.org/10.1111/nep.13601.

Persistent Link:

http://hdl.handle.net/11343/285966 